\title{
Pengukuran Metrik Kompleksitas Model Proses Bisnis Pondok Pesantren
}

\author{
Muhammad Ainul Yaqin', Dian Permana Putra ${ }^{2}$, Faizal Armas Fata ${ }^{3}$, Lailatul \\ Maghfiroh $^{4}$ \\ 1,2,3,4 Jurusan Teknik Informatika, UIN Maulana Malik Ibrahim Malang
}

yaqinov@ti.uin-malang.ac.id ${ }^{1}$, 16650108@student.uin-malang.ac.id ${ }^{2}$, 16650086@student.uin-malang.ac.id ${ }^{3}$, 16650036@student.uin-malang.ac.id ${ }^{4}$

Received : November, 2019

Accepted : November, 2019

Published : Desember, 2019

\begin{abstract}
ABSTRAK.
Organisasi bisnis dunia saat ini banyak memanfaatkan sistem informasi digital untuk memberikan pemahaman mengenai manajemen proses bisnis yang mereka jalankan tak terkecuali pondok pesantren. Untuk mengetahui kualitas dari pada proses bisnis pondok pesantren tersebut dilakukan pemodelan pada proses bisnis yang nantinya dijadikan sebagai proyek pengukuran sebuah proses bisnis dalam pondok pesantren. Oleh sebab itu dilakukan proses perhitugan melalui indeks-indeks metrik pada model proses bisnis pondok pesantren. Hal ini merupakan dasar pertimbangan yang dijadikan acuan untuk menghitung metrik-metrik yang dapat diperoleh dari pemodelan proses bisnis yang ada. Dalam makalah ini, dilakukan perhitungan terhadap model proses bisnis dari pondok pesantren melalui jenis diagram BPMN.
\end{abstract}

Kata Kunci: Proses Bisnis; BPMN; Metrik

\begin{abstract}
Today's world business organizations make use of digital information systems to provide an understanding of the management of business processes that they run, including boarding schools. To find out the quality of the boarding school business process, a modeling of the business process is carried out which will be used as a project to measure a business process in the boarding school. Therefore, the calculation process is carried out through metric indices in the boarding school business process model. This is a basic consideration that is used as a reference for calculating the metrics that can be obtained from modeling existing business processes. In this paper, a calculation of the business process model of the boarding school is carried out through BPMN diagram types.
\end{abstract}

Keywords: Business Process; BPMN; Metric

\section{PENDAHULUAN}

Proses Bisnis merupakan sekumpulan aktivitas yang dibuat untuk menghasikan keluaran spesifik dengan tujuan tertentu.[1]. Proses bisnis dapat dikatakan juga dengan sebuah usaha-usaha yang dilakukan dalam mencari, menemukan, mengumpulkan sesuatu, sampai pada mengolah sesuatu tersebut sehingga dapat menghasilkan sesuatu yang baru yang diharapkan dapat membantu untuk mencapai suatu tujuan tertentu.

Pemodelan proses bisnis adalah salah satu cara merepresentasikan suatu aktivitas proses bisnis menjadi bentuk diagram maupun grafis yang saat ini berkembang cukup pesat [1]. Pemodelan proses bisnis dapat dikatakan pula sebagai representasi objek nyata atau realita sebagai seperangkat persamaan matematika, grafis ataupun bagan agar mudah dipahami oleh pihak yang berkepentingan.

Model proses bisnis, dapat dinotasikan dalam diagram BPMN, di mana hal ini berfungsi sebagai dasar untuk komunikasi antara pemegang saham dalam proses pengembangan perangkat lunak. Untuk mencapai harapan tersebut, model proses bisnis mestinya mudah dimengerti dan mudah dipelihara [2]. Dibutuhkan tahapantahapan yang dapat mendukung beberapa informasi mengenai pemahaman dan pemeliharaan model proses bisnis. Tahapan-tahapan tersebut menjadi cara untuk kita megetahui apakah model mempunyai ukuran yang sesuai, tersusun dengan jelas, dan mudah dipahami. Dari metrik yang diperoleh dapat dirumuskan bahwa model harus direkayasa ulang, misalnya dengan menguraikan menjadi proses yang lebih simpel [2]. Makalah ini membahas bagaimana menghitung metrik kompleksitas model proses bisnis pondok pesantren sehingga 
harapannya hasil perhitungan metrik kompleksitas yang diperoleh dapat diperluas untuk pengembangan, pertumbuhan maupun perhitungan unit cost proses bisnis.

Metrik-metrik pada model proses bisnis dikumpulkan sebagai pengukuran indikator proses bisnis. Indikator proses memungkinkan sebuah organisasi untuk memperoleh pengetahuan mengenai reliabilitas sebuah proses yang sedang berlangsung (misalnya paradigma, tugas-tugas, produk kerja, dan kejadian penting). Indikator proses memungkinkan untuk meninjau dan memperkirakan apa yang harus terlebih dahulu dikerjakan. Metrik proses dikumpulkan di seluruh proyek dan pada perkembangan proses bisnis jangka panjang. Indikator proses bisnis memungkinkan untuk manajemen proses bisnis:

a. Memperkirakan status sebuah proses bisnis yang sedang berlangsung,

b. Menelusuri resiko-resiko potensial,

c. Menemukan titik masalah sebelum masalah menjadi semakin rumit,

d. Menyesuaikan aliran kerja atau tugas-tugas, dan

e. Mengevaluasi kemampuan proses untuk mengontrol kualitas hasil kerja.

Indeks- indeks metrik yang diterapkan untuk mengukur model proses bisnis antara lain: Size, Activity Size, Resources Size, Resources Coupling, Event Size, Start Event Size, End Event Size, Intermediate Event Size, Connector Size, And Split Size, And Join Size, Or Split Size, Or Join Size, Xor Split Size, Xor Join Size, Control Flow Complexity, Diameter, Density, Coefficient of Connectivity, Activity coupling, Sequentiality dan Cognitive Complexity.

22 aspek tersebut diharapkan dari hasil yang diperoleh dapat digunakan untuk pengembangan proses bisnis kedepannya sehingga apa yang menjadi tujuan dapat tercapai di mana hal ini sesuai dengan yang diungkapkan Sanjaya [3] bahwa tujuan dari pembuatan perangkat lunak adalah untuk menciptakan perangkat lunak yang berkualitas, sama halnya pada proses bisnis. Tujuan dari pengukuran kompleksitas model proses bisnis adalah jalan awal untuk menciptakan proses bisnis yang berkualitas, efektif dan efisien.

\subsection{Rancangan Penelitian}

\section{METODE PENELITIAN}

Penelitian bertujuan untuk mengukur metrik kompleksitas model proses bisnis pondok pesantren. Setelah mendapatkan data yang dibutuhkan, dilanjutkan dengan melakukan analisis data. Penelitian dilakukan melalui wawancara dan juga studi dokumen. Penelitian yang dibuat mengacu pada SOP dan pemodelan proses bisnis. Metodologi penelitian dapat dijelaskan dengan flowchart pada gambar 1 untuk lebih mempermudahkan dalam melihat tahapan-tahapannya.

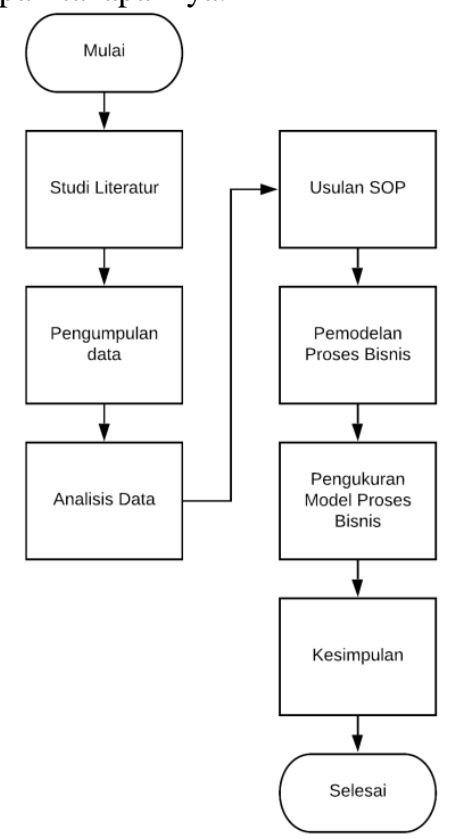

Gambar 1. Flowchart Metodologi Penelitian 


\subsection{Teknik Pengumpulan Data}

Dalam penelitian ini, teknik pengumpulan data yang digunakan adalah studi dokumen dan wawancara.

- Studi Dokumen

Studi dokumen yaitu mengumpulkan data dengan cara memepelajari dan menganalisis jurnal, file, dokumen yang berbentuk cetak atau tertulis sebagai sumber informasi tentang teori yang berhubungan dengan permasalahan penelitian beserta objek yang akan diteliti.

- Wawancara

Wawancara dilakukan secara lisan antara peneliti kepada yang bersangkutan terkait penelitian dan sudah dipilih oleh peneliti. Peneliti mewawancarai santri yang mengerti tentang proses bisnis dan memiliki tanggung jawab di pondok pesantren, hal ini bertujuan untuk mendapatkan hasil gambaran yang jelas tentang proses bisnis sanksi pelanggaran, akomodasi dan kesehatan.

\subsection{Sumber Data}

Sumber data yang digunakan dalam penelitian ini yaitu data primer dan data sekunder, berikut uraiannya:

- Data Primer

Data primer merupakan data yang dikumpulkan, dicatat dan diolah sendiri oleh peneliti langsung dari obyeknya berupa pertanyaan, penjelasan dan keterangan dari keamanan pondok pesantren yang terkait langsung dengan persoalan proses bisnis sanksi pelanggaran, akomodasi dan kesehatan.

- Data Sekunder

Data sekunder adalah data yang didapat secara tidak langsung atau data tersebut telah dikumpulkan oleh pihak lain yang dikumpulkan peneliti sebagai penunjang pembuatan penelitian. Atau data-data yang tersusun dalam bentuk dokumen seperti jurnal yang terkait pada topik penelitian.

\subsection{Analisis Data}

Dari hasil wawancara yang telah kami lakukan, kemudian kami melakukan pengelompokkan data di mana data-data tersebut terkelompok dalam deskripsi proses sanksi pelanggaran, akomodasi dan juga kesehatan. Pada tahap selanjutnya kami melakukan studi dokumen yang ada tentang pondok pesantren. Kami mengkombinasikan deskripsi hasil wawancara dengan studi dokumen yang ada sehingga dapat dibuatkan SOP untuk bagian sanksi pelanggaran, akomodasi dan juga kesehatan di mana SOP tersebut kita gunakan untuk membuat model proses bisnis melalui diagram BPMN.

\section{HASIL DAN PEMBAHASAN}

Studi kasus yang kami hitung metrik kompleksitasnya adalah pada sub bagian keamanan, akomodasi dan kesehatan pondok. Sesuai dengan yang telah disebutkan pada bab 1, kami mencoba mengukur indeks-indeks metrik kompleksitas model proses bisnis. Pertama-tama yang kami lakukan adalah memodelkan proses bisnis dalam bentuk notasi BPMN, sehingga bisa dihitung kompleksitasnya. Adapun notasi BPMN dari model proses bisnis Sanksi Pelanggaran (SP) adalah seperti yang ditunjukkan pada gambar 2.

\subsection{Sanksi Pelanggaran}

- Metrik Size

Size adalah seluruh jumlah node pada model proses bisnis [4].

Sehingga, $S_{N}(S P)=23$

$$
S_{N}(G)=|\mathbf{N}|
$$

- Metrik Activity Size

Activity Size mewakili jumlah (task) tugas Bisnis Proses [5].

$$
\operatorname{Size}_{A}(p)=\sum_{i=1}^{n_{r}} \operatorname{Size}_{A}\left(\text { task }_{i}\right)+\sum_{i=1}^{n s r} \text { Size }_{A}\left(\text { supertask }_{i}\right)
$$

Sehingga, $\operatorname{Size}_{A}(S P)=18+0=18$

- Metrik Resource Size 
Resource Size mempertimbangkan semua sumber daya yang dibutuhkan dan digunakan oleh grafik Proses Bisnis selama proses eksekusi [5].

$$
\operatorname{Size}_{R}(p)=\sum_{i=1}^{n_{r}} r_{t=R}
$$

Sehingga, $\operatorname{Size}_{\boldsymbol{R}}(\boldsymbol{S P})=3$. Pada BPM tersebut ada 3 pelaksana kegiatan, yakni: Orang tua, Pengurus, dan Santri.

- $\quad$ Metrik Resource Coupling

Resource Coupling adalah metrik yang menghubungkan "sumber daya" dan hubungan antara kegiatan di dalamnya [5].

$$
\operatorname{Coupling}_{R}(p)=H
$$

Di mana $\mathrm{H}$ adalah jumlah transisi antara dua aktivitas yang menjadi milik swim lane yang berbeda: $\operatorname{Coupling}_{R}(\mathrm{SP})=\mathbf{8}$

- Metrik Event Size

Event Size adalah metrik yang menghitung jumlah "Kejadian” dalam Proses Bisnis [4].

$$
\begin{gathered}
\operatorname{Size}_{E}(p)=\sum_{t \in E_{\text {Event }}} \operatorname{Size}_{E}(t) \\
\text { di mana } \operatorname{Size}_{E}(t)=1
\end{gathered}
$$

Sehingga, $\operatorname{Size}_{\boldsymbol{E}}(\boldsymbol{S P})=\mathbf{2}$

- $\quad$ Metrik Start Event Size

Start Event Size adalah metrik yang menghitung jumlah Peristiwa Mulai dalam Proses Bisnis [4].

$$
\begin{gathered}
\operatorname{Size}_{S E}(P)=\sum_{\substack{t \in \text { Event-start } \\
\text { di mana } \\
\operatorname{Size}_{S E}(t)=1}} \text { Size }_{S E}(t) \\
\text { ing }
\end{gathered}
$$

Sehingga, $\operatorname{Size}_{S E}(\boldsymbol{S P})=1$

- Metrik End Event Size

End Event Size adalah metrik yang menghitung jumlah Kejadian Akhir dalam Proses Bisnis [4].

$$
\begin{aligned}
& \operatorname{Size}_{E E}(p)=\sum_{\substack{t \in \text { Event-end } \\
\text { di mana }}} \operatorname{Size}_{E E}(t) \\
& \operatorname{Size}_{E E}(t)=1
\end{aligned}
$$

Sehingga, $\operatorname{Size}_{E \boldsymbol{E}}(\boldsymbol{S P})=1$

- Metrik Intermediet Event Size

Intermediet Event Size adalah metrik yang menghitung jumlah Peristiwa Menengah dalam Proses Bisnis [4].

$$
\operatorname{Size}_{I E}(p)=\sum_{\substack{t \in \text { Event-intermediate }_{\text {di mana }} \\ \operatorname{Size}_{I E}(t)=1}} \operatorname{Size}_{I E}(t)
$$

Sehingga, $\operatorname{Size}_{\boldsymbol{I E}}(\boldsymbol{S P})=\mathbf{0}$. Tidak terdapat Intermediet Event pada Proses Bisnis Sanksi Pelanggaran (SP).

- Metrik Connector Size

Connector Size adalah menghitung jumlah konektor, dibagi dalam And, Or, dan Xor [4]. 


$$
=\sum_{r t \in A N D} \operatorname{Size}_{A N D}(r t)+\sum_{r t \in O R-S p l i t} \operatorname{Size}_{O R}(r t)+\sum_{r t \in X O R} \operatorname{Size}_{X O R}(r t)
$$

Sehingga, ConnectorSize $(\mathrm{SP})=0+0+3=3$

- $\quad$ Metrik And Split Size

And Split Size adalah menghitung jumlah konektor 'Dan' Pembagi [4].

$$
\operatorname{Size}_{A S}(p)=\sum_{r t \in A N D-s p l i t} \text { Size }_{A N D-s p l i t}(r t)
$$

Sehingga, $\operatorname{Size}_{\boldsymbol{A}}(\boldsymbol{S P})=\mathbf{0}$

- $\quad$ Metrik And Join Size, menghitung jumlah konektor 'Dan’ Bergabung [4].

$$
\operatorname{Size}_{A J}(p)=\sum_{r t \in A N D-\text { join }} \operatorname{Size}_{A N D-\text { join }}(r t)
$$

Sehingga, $\operatorname{Size}_{A J}(\mathbf{S P})=\mathbf{0}$

- $\quad$ Metrik Or Split Size, menghitung jumlah konektor 'Atau' Pembagi [4].

$$
\operatorname{Size}_{O S}(p)=\sum_{r t \in O R-s p l i t} \operatorname{Size}_{O R-s p l i t}(r t)
$$

Sehingga, $\operatorname{Sizeos}(\mathbf{S P})=0$

- Metrik Or Join Size, menghitung jumlah konektor 'Atau’ Bergabung [4].

$$
\operatorname{Size}_{O J}(p)=\sum_{r t \in O R-\text { join }} \text { Size }_{O R-\text { join }}(r t)
$$

Sehingga, $\operatorname{SizeoJ}(\mathbf{S P})=0$

- $\quad$ Metrik Xor Split Size, menghitung jumlah konektor Xor pembagi [4].

$$
\operatorname{Size}_{X S}(p)=\sum_{r t \in O R-s p l i t} \operatorname{Size}_{O R-s p l i t}(r t)
$$

Sehingga, $\operatorname{Size}_{\boldsymbol{X}}(\mathbf{S P})=\mathbf{3}$

- Metrik Xor Join Size, menghitung jumlah konektor Gabung Xor [4].

$$
\operatorname{Size}_{X J}(p)=\sum_{r t \in O R-\text { join }} \text { Size }_{X O R-j o i n}(r t)
$$

Sehingga, $\operatorname{Size}_{X J}(\mathbf{S P})=0$

- $\quad$ Metrik Control Flow Complexity

Kompleksitas Aliran Kontrol untuk proses SP adalah penjumlahan kompleksitas yang berasal dari perpecahan sebagai [5]:

$$
=\sum_{r t \in A N D-s p l i t} C F C_{A N D-s p l i t(r t)}+\sum_{r t \in O R-s p l i t} C F C_{O R-s p l i t}(r t)+\sum_{r t \in X O R-s p l i t} C F C_{X O R-s p l i t}(r t)
$$

Sehingga, Complexity $F(S P)=0+0+3=3$

- Metrik Diameter adalah panjang jalur terpanjang dari simpul awal ke simpul akhir dalam model proses [4].

Sehingga, $\operatorname{diam}(\mathbf{S P})=16$

$$
\operatorname{diam}(\mathbf{S P})=\mathbf{n}
$$


Vol. 11 No. 2 - Desember 2019 p-ISSN 2086-3489 (Print)- e-ISSN 2549-354X (Online) Avaiable online at http://jurnal.yudharta.ac.id/v2/index.php/EXPLORE-IT/

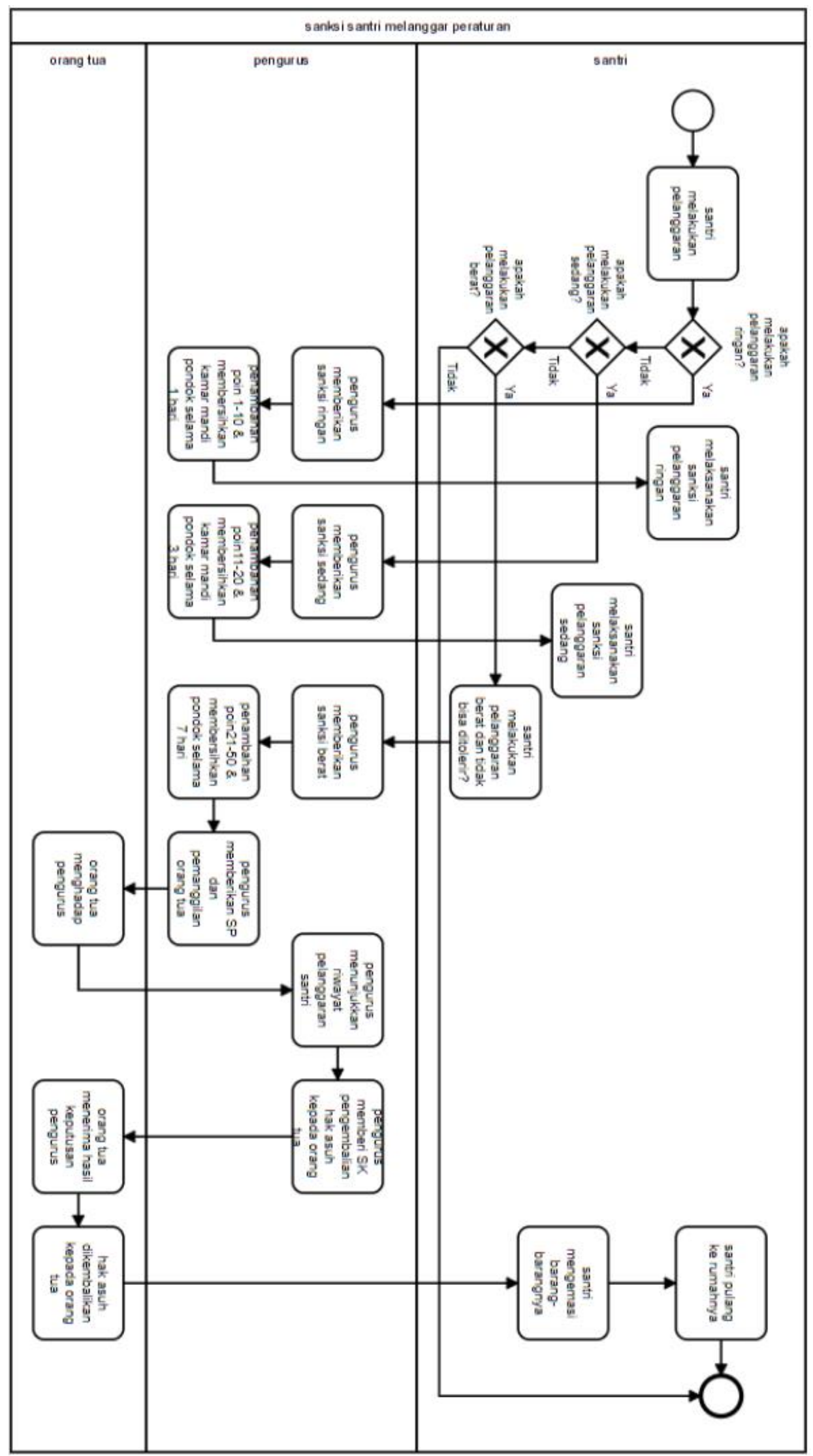

Gambar 2. Notasi BPMN dari proses bisnis SP 
- Metrik Density adalah jumlah busur (A) dibagi dengan jumlah busur maksimum untuk jumlah node yang sama $(\mathrm{N})[4]$.

$$
\Delta(G)=\frac{|A|}{|N| \cdot(|N|-1)}
$$

Sehingga, $\Delta(S P) \quad=|23| /|23| \times(|23|-1)$

$$
\begin{aligned}
& =23 /(23 \times 22) \\
& =23 / 506=0.0455
\end{aligned}
$$

- Metrik Coefficient of Connectivity, mewakili rasio busur (A) ke node (N) [4].

$$
\operatorname{CNC}(G)=\frac{|A|}{|N|}
$$

Sehingga, $\boldsymbol{C N C}(\boldsymbol{S P})=|23| /|23|=1$

- Metrik Activity Coupling, merepresentasikan rasio dari simpul ke busur [4].

$$
N C A(G)=\frac{|N|}{|A|}=\frac{1}{C N C}
$$

Sehingga, $\boldsymbol{N C A}(S P)=1 / 1=1$

- Metrik Sequentiality adalah jumlah busur antara node non-konektor dibagi dengan jumlah busur [4].

$$
\Xi(G)=\frac{|A \cap(T \times T)|}{|A|}
$$

Sehingga, ${ }^{\Xi}(S P)=16 / 23=0.69565$

\begin{tabular}{|c|c|c|}
\hline$B P M N$ structure & $\begin{array}{l}B P M N \\
\text { symbol }\end{array}$ & $\begin{array}{c}\text { Cognitive } \\
\text { weight }\end{array}$ \\
\hline Single consecutive step in a work-flow & $(-\infty)+(-\infty)+\infty+\infty)$ & 1 \\
\hline $\begin{array}{l}\text { All joins. In [33], the metric was originally defined only for business process } \\
\text { models that are well-structured. In BPMN, corresponding joins are not } \\
\text { necessary. The weight of join elements is considered as equal to the cognitive } \\
\text { weight of sequence elements. }\end{array}$ & ${ }_{i=1}^{i=2}$ & 1 \\
\hline XOR-split (exactly one of two branches is chosen) & & 2 \\
\hline XOR-split (exactly one of more than two branches is chosen) & 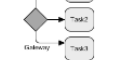 & 3 \\
\hline AND-split & \pm & 4 \\
\hline OR-split or Complex Gateway & $0^{\circ}$ & 7 \\
\hline Sub-process (can be used for decomposing BPMN models) & $-\infty$ & 2 \\
\hline Start or End event & $0 \cdot T$ & 2 \\
\hline $\begin{array}{l}\text { Intermediate event (both intermediate events attached to the boundary } \\
\text { of activities and intermediate events within the normal fows) }\end{array}$ & $=0 \cdot \pi$ & 3 \\
\hline
\end{tabular}

- Cognitive Complexity

Ukuran kompleksitas kognitif merupakan bobot kognitif yang dimaksudkan guna mengukur upaya yang dibutuhkan dalam memahami model [6]. Bobot kognitif disimbolkan dengan huruf W. Nilai W yang rendah menjadi tujuan yang ingin didapatkan karena nilai $\mathrm{W}$ yang lebih tinggi, berarti semakin sulit untuk memahami model [6].

Gambar 3. Tabel Proposisi bobot kognitif untuk BPMN dalam Ukuran Kompleksitas Kognitif [6].

Sesuai proporsi bobot kognitif pada gambar 3, Sehingga model proses bisnis Sanksi Pelanggaran(SP) memiliki bobot sebesar 13 .

\subsection{Akomodasi}

Standar pondok pesantren yang diusulkan untuk akomodasi pondok pesantren yang baik dari segi perlengkapan dan peralatan bebas dari kerusakan, fasilitasnya mudah diakses dan digunakan santri berkebutuhan khusus, dikelompokkan sesuai dengan umur, dan jumlah kebutuhan kamar Kami mengusulkan SOP kriteria asrama pada pondok pesantren yang sesuai standar sebagai berikut: 
1. Pondok pesantren harus memiliki asrama yang perlengkapan dan peralatan bebas dari kerusakan, jika tidak maka asrama harus diperbaiki sesuai dengan standart yang disebutkan.

2. Pondok pesantren harus memiliki asrama yang fasilitasnya mudah diakses dan digunakan santri berkebutuhan khusus, jika tidak maka asrama harus diperbaiki sesuai dengan standart yang disebutkan.

3. Pondok pesantren harus memiliki asrama yang sudah dikelompokkan sesuai dengan umur, jika tidak maka asrama harus diperbaiki sesuai dengan standart yang disebutkan.

4. Pondok pesantren harus memiliki asrama yang sesuai dengan jumlah kebutuhan kamar, jika tidak maka asrama harus diperbaiki sesuai dengan standart yang disebutkan.

Dari SOP di atas dimodelkan dalam diagram BPMN seperti yang ditunjukkan gambar 4.

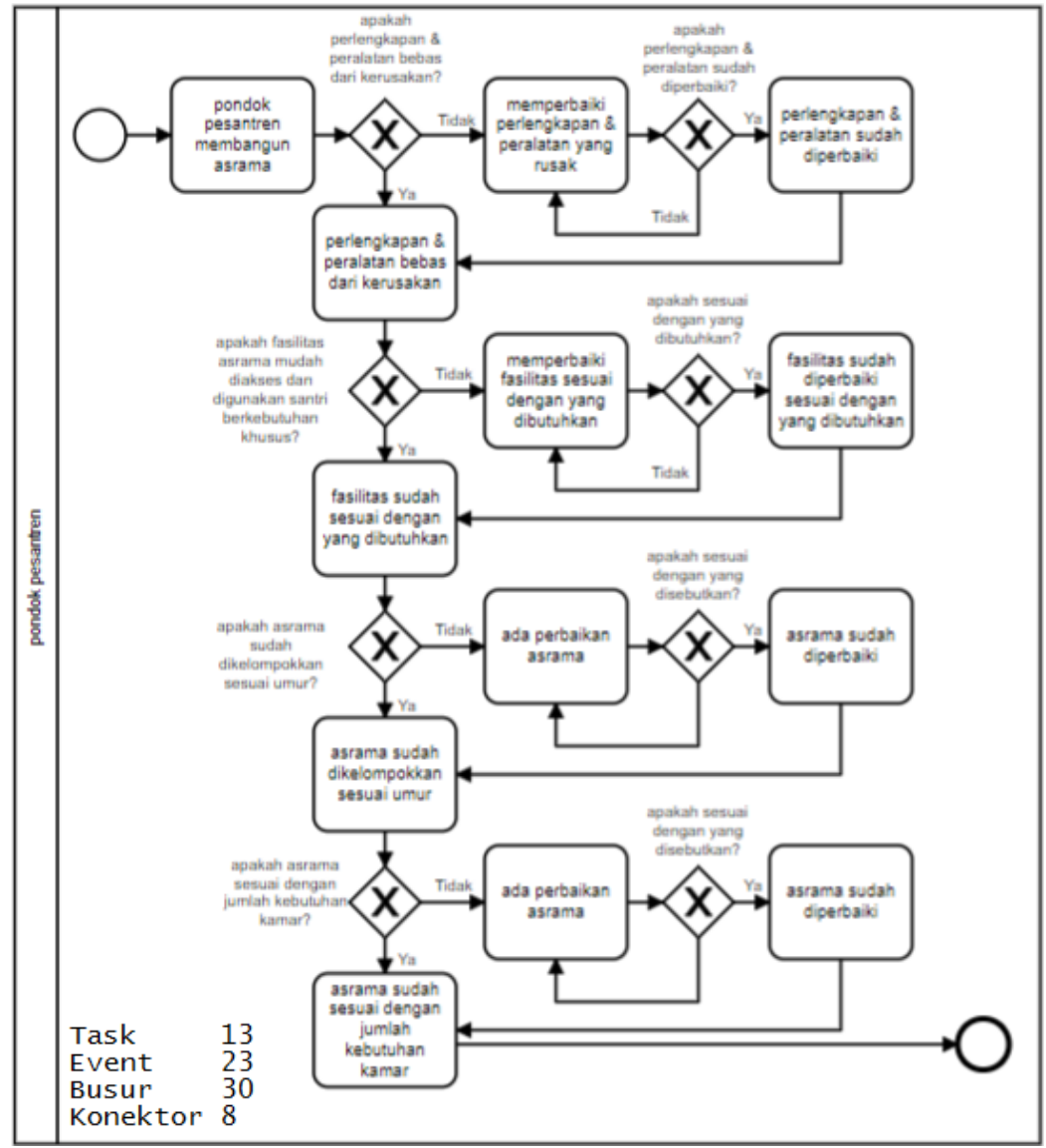

Gambar 4. Notasi BPMN dari proses bisnis akomodasi segi perlengkapan \& peralatan

Dengan menggunakan rumus 1 hingga 21 dan cara perhitungan yang sama, kami menghitung metrik kompleksitas model proses bisnis pada gambar 4, sehingga diperoleh hasil perhitungan metrik-metrik seperti yang ditunjukkan pada tabel 1.

Tabel 1: Hasil pengukuran metrik segi perlengkapan \& peralatan model proses bisnis akomodasi

\begin{tabular}{|l|c|c|}
\hline No & Metrik & Hasil \\
\hline 1. & Size & 23 \\
\hline 2. & Activity Size & 13 \\
\hline 3. & Resource Size & 1 \\
\hline 4. & Resource Coupling & 0 \\
\hline 5. & Event Size & 2 \\
\hline 6. & Start Event Size & 1 \\
\hline
\end{tabular}




\begin{tabular}{|l|c|c|}
\hline 7. & End Event Size & 1 \\
\hline 8. & Intermediet Event Size & 0 \\
\hline 9. & Connector Size & 8 \\
\hline 10. & And Split Size & 0 \\
\hline 11 & And Join Size & 0 \\
\hline 12. & Or Split Size & 0 \\
\hline 13. & Or Join Size & 0 \\
\hline 14. & Xor Split Size & 8 \\
\hline 15. & Xor Join Size & 0 \\
\hline 16. & CFC & 8 \\
\hline 17. & Diameter & 23 \\
\hline 18. & Density & 0,059 \\
\hline 19. & CNC & 1,304 \\
\hline 20. & NCA & 0,766 \\
\hline 21. & Sequentiality & 0,214 \\
\hline 22. & Cognitive Complexity & 24 \\
\hline
\end{tabular}

\subsection{Kesehatan}

Standar pondok pesantren diusulkan untuk menerapkan perwatan sebagai pertolongan pertama dari petugas UKS untuk santri yang sakit. Kami mengusulkan SOP pemberian pertolongan pertama pada santri yang sakit sebagai berikut :

1. Santri merasakan gejala sakit ataupun keluhan.

2. Santri datang ke Unit Kesehatan Sekolah (UKS).

3. Petugas UKS menanyakn keluhan kepada santri.

4. Santri menjelaskan keluhan yang dirasakan kepada petugas UKS.

5. Petugas UKS memeriksa santri dan memberikan obat sesuai keluhannya.

6. Santri menerima obat yang diberikan petugas UKS dan membayarnya.

7. Petugas UKS menerima pembayaran dari santri

Dari SOP di atas dimodelkan dalam diagram BPMN seperti yang ditunjukkan gambar 5.

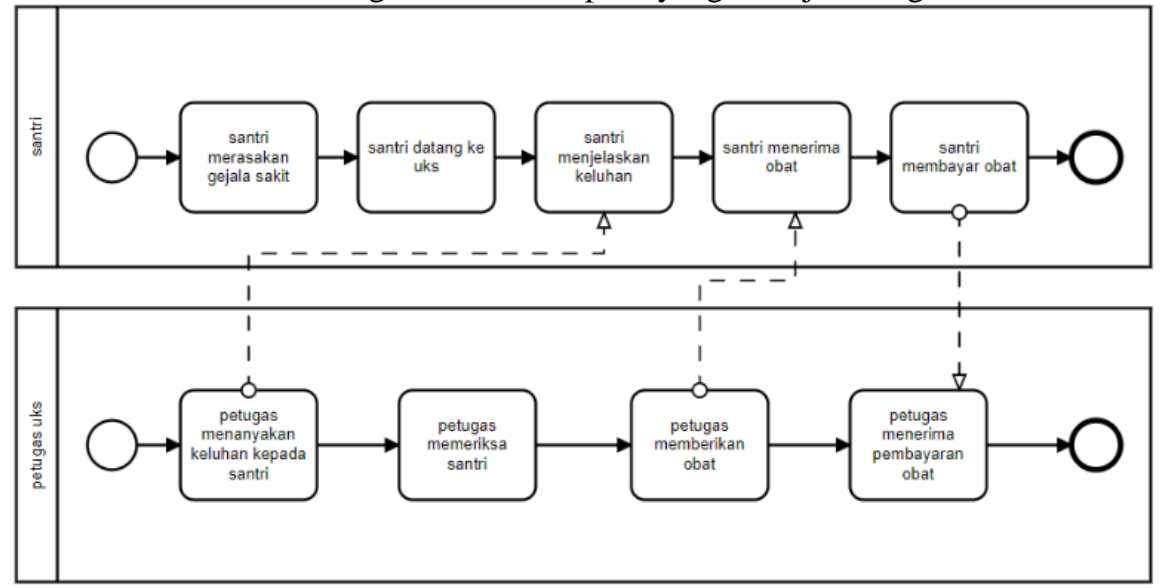

Gambar 5. Notasi BPMN dari proses bisnis kesehatan segi perwatan santri yang sakit

Dengan menggunakan rumus 1 hingga 21 dan cara perhitungan yang sama, kami menghitung metrik kompleksitas model proses bisnis pada gambar 5, sehingga diperoleh hasil perhitungan metrik-metrik seperti yang ditunjukkan pada tabel 2. 
Tabel 2: Hasil pengukuran metrik segi perawatan santri model proses bisnis kesehatan

\begin{tabular}{|l|c|c|}
\hline No & Metrik & Hasil \\
\hline 1. & Size & 13 \\
\hline 2. & Activity Size & 2 \\
\hline 3. & Resource Size & 3 \\
\hline 4. & Resource Coupling & 4 \\
\hline 5. & Event Size & 2 \\
\hline 6. & Start Event Size & 2 \\
\hline 7. & End Event Size & 0 \\
\hline 8. & Intermediet Event Size & 0 \\
\hline 9. & Connector Size & 0 \\
\hline 10. & And Split Size & 0 \\
\hline 11 & And Join Size & 0 \\
\hline 12. & Or Split Size & 0 \\
\hline 13. & Or Join Size & 0 \\
\hline 14. & Xor Split Size & 0 \\
\hline 15. & Xor Join Size & 9 \\
\hline 16. & CFC & 0,089 \\
\hline 17. & Diameter & 1,076 \\
\hline 18. & Density & 0,928 \\
\hline 19. & CNC & 1,16 \\
\hline 20. & Nequentiality & 13 \\
\hline 21. & Cognitive Complexity & 0 \\
\hline 22. & & \\
\hline & & \\
\hline
\end{tabular}

\section{KESIMPULAN}

Dalam makalah ini kami telah mengukur beberapa metrik kompleksitas di bagian sanksi pelanggaran, akomodasi dan kesehatan pada model proses bisnis pondok pesantren. Selanjutnya diharapkan dilakukan pengukuran terhadap bagian lain dari model proses bisnis pondok pesantren sehingga nantinya hasil pengukuran metrik dapat digunakan untuk mengukur understanbility, maintainability, kualitas model proses bisnis maupun pengukuran-pengukuran yang lain di mana pengukuran tersebut dibutuhkan untuk pertumbuhan pondok pesantren karena hal ini berada di luar cakupan makalah ini dan harus dilakukan dalam penelitian masa depan.

\section{DAFTAR PUSTAKA}

[1] Weske, M. Business Process Management Concept, Languages, Architectures, Berlin: Springer, 2007.

[2] Gruhn, V. \& Laue, R. "Complexity Metrics for business Process Models". Lecture Notes in Informatics (LNI), Proceedings - Series of the Gesellschaft fur Informatik (GI). 1-12, 2008.

[3] C. B. Sanjaya, "Evaluasi Spesifikasi Kebutuhan Perangkat Lunak Berdasarkan Software Quality Model”, EXPLORIT, vol. 7, no. 2, Dec. 2015.

[4] Mendling, J. Metrics for Business Process Models:Empirical Foundations of Verification, Error Prediction, and Guidelines for Correctness, Berlin: Springer, 2008.

[5] Antonini, A., Ferreira, A.M., Morascan, S., \& Pozzi, G. "Software Measure for Business". Process.In: Proc. II of the15th East-European Conference on Advances in Databases and Information Systems, Vienna, Austria, September 20 - 23, 2011.

[6] Sadowska, M. "An Approach to Assessing the Quality of Business Process Models Expressed in BPMN". 9. 57-77, 2015. 